\title{
Intention to Purchase Chapters of Online Literature: A Pilot Study in Thailand
}

\author{
Duangkamol Chuengprapa $^{1} \&$ Nitaya Wongpinunwatana ${ }^{2}$ \\ ${ }^{1}$ Cloudforce HR Co., Ltd., Bangkok, Thailand \\ ${ }^{2}$ Thammasat Business School, Thammasat University, Bangkok, Thailand \\ Correspondence: Nitaya Wongpinunwatana, Thammasat Business School, Thammasat University, Bangkok, \\ Thailand.
}

\author{
Received: March 9, 2018 \\ Accepted: April 17, 2018 \\ Online Published: May 9, 2018 \\ doi:10.5539/ibr.v11n6p11 \\ URL: https://doi.org/10.5539/ibr.v11n6p11
}

\begin{abstract}
The purpose of this study is to examine the factors that influence the intention to purchase chapters of online literature. This study is based on descriptive research using an online survey. The results indicate that six factors (favorable attitude from social norms, functional dependence on platform, emotional attachment to content creator, perceived benefit, perceived sacrifice, and perceived value) can be used to predict the intention to purchase online literature. The findings of this research will help practitioners by providing a guideline to improve products and services. This research combines the value intention model, status quo bias theory, and integration of attachment theory and socio-technical systems, and as far as the author knows, these theories have never before been studied together.
\end{abstract}

Keywords: chapter purchase, freemium, online literature, fee-based platform, paid-online content

\section{Introduction}

Online or digital literature - including novels, poetry, essays, comic series, and other works - is a genre of literature published online for digital devices (Aarseth, 1997). Online literature originated as a non-professional literary phenomenon which encouraged amateurs to share content with one another for free on the internet. The content creators are motivated by the desire for creative expression, popularity, and sense of belonging, rather than for financial benefits. These factors also are important in producing user-generated content in other areas (Shirky, 2010; Ren \& Montgomery, 2012).

In 1999, a few literature websites were established with strategies for monetizing user-generated content. The changes of reader habits, from printed matter to online, influenced the increasing size and number of online communities (Ren \& Montgomery, 2012). A survey in 2015 indicated that readers over the age of six years increasingly intend to change their ways of reading from books to electronic sources (National Statistical Office, 2016). Consequently, these online literature platforms have become channels for non-professional writers to build their reputations, to evaluate their popularity, and to have opportunities to step up as professional writers.

In China, online literature platforms have developed micropayment strategies with "freemium" business models which allow non-professional writers or content creators to publish their own literature and sell them online (Ren \& Montgomery, 2012). Micropayments refer to electronic transactions of small amounts of money, which are usually less than one US dollar (Kotliar, 2011). With this model, the readers are permitted to read a limited amount of content for free before making a purchase. Some serialized literature can be accessed free of charge; but if it becomes popular, it will be converted to VIP content, and the readers will be required to pay for access to additional chapters (Liu, 2010; Ren \& Montgomery, 2012). The readers who do not want to wait until the literature is printed or published as an e-book can obtain the privilege to read as soon as the new chapters are released. In Thailand, moreover, the strategy has recently been adopted by platforms such as Dek-D, Comico, Fictionlog, ReadAWrite, and Tunwalai.

Although the adoption of new technologies such as e-books in the publishing field have been widely accepted by Thai readers (Ngamkaiwan, 2014), a survey on reading behavior implied that the majority of readers who have read an e-book at least once, have never actually purchased an e-book (Econ Chula \& SAB, 2015). In other words, the readers have received free e-books provided for advertising purposes. Nevertheless, even though the 
free trial may attract users to participate and contribute their resources, it becomes a double-edged sword. A study in 2001 showed that the greater the users are familiar with free content, the less they are willing to pay for content (Gallaugther et al., 2001). The belief that online content should be free persists in people's minds. Thus, this paywall has become a major obstacle for platforms in developing strategies for online literature sales.

A survey of purchasing behaviors of Thai readers in 2015 also proved that the electronic market is still small compared with the printed book market (Econ Chula \& SAB, 2015). Moreover, introducing new channels to purchase online literature with a micropayment or chapter purchasing strategy on the platform might affect perception and intention of the users to pay for the content (Ren \& Montgomery, 2012). According to the literature review, the purchase intention of online content, such as online music, is also supported by the value intention model and status quo bias (Lin et al., 2013; Li \& Cheng, 2014). In addition, as the researchers also believed that the chapter purchasing model can tighten the relationship between authors and readers, it is essential to apply the integration of attachment theory and socio-technical systems in this research in order to improve effectiveness of business strategies; these have never before been studied together with the value intention model and status quo bias, especially in the online literature platform.

This research aims to explore and understand factors that influence consumer opinions and purchase decisions in fee-based online literature platforms. The results of this study can be utilized to improve products and services provided on the platforms, to encourage willingness of the readers to spend further, as well as creating long-term viability of online literature platforms.

\section{Theoretical Background}

This section provides information on important factors which predict the intention to purchase chapters of online literature. These factors extract from the value intention model, status quo bias theory, and integration of attachment theory and socio-technical systems. The value intention model assumes that perceived value directly affects the willingness to do a certain action. In other words, perceived value is a key factor in the process of a consumer's purchasing decision. The greater the perceived value, the more the customer is influenced to purchase (Dodds \& Monroe, 1985; Chi et al., 2011). Status quo bias theory explains the consumer's preference in maintaining their current situations or statuses (Samuelson \& Zeckhauser, 1988). The previous studies of status quo bias theory showed that social norms can significantly affect consumer's perceived benefits (Kim \& Kankanhalli, 2009; Li \& Cheng, 2014). Finally, the integration of attachment theory and socio-technical systems implies that both emotional attachment and functional dependence have positive relationships to the behavioral intention (Wan et al., 2016). The factors affecting intention to purchase chapters of online literature follow.

Favorable Attitude from Social Norms refers to positive opinions from others which affect individual perception in valuation and the decision-making process due to the need of social companionship. The endorsement or favorable attitude towards paid online content from influencers - such as friends, families, colleagues, classmates, and online communities - can reduce status quo bias and encourage individuals to engage in social norms (Samuelson \& Zeckhauser, 1988; Kim \& Kankanhalli, 2009; Li \& Cheng, 2014).

Functional Dependence on Platform refers to the degree that a consumer relies on functions on a platform which are designed to support and satisfy the consumer. The functions include discussion channels, share features, follow features, display customization, and consumer recommendations. These functions have an influence on behavior and mental state of the consumer. The willingness of time and financial sacrifice to obtain an object can be encouraged by an individual's strong attached dependence. In online communities, the users should have different perceptions and behavior across different degrees of functional dependence. The greater the effectiveness of functional tools is supported, the more the users tend to engage and contribute resources on the platform. (Sohn \& Leckenby, 2007; Chu \& Lu, 2007; Xu et al., 2012; Lin et al., 2013; Wan et al., 2016)

Emotional Attachment to a Content Creator refers to the emotional feeling that reflects the desire to maintain a relationship with the author as the user's affective commitment. In the publishing field, users respond more strongly to a story written by their favorite authors since they realize that most authors have their own unique style of writing. The stronger attachment should lead to greater contributions of consumers' resources, such as time and energy, to strengthen their relationship with the content creators (Holmes, 2000; Fedorikhin et al., 2008; Choi, 2013; Saarinen \& Vakkari, 2013; Prasert, 2014; Wan et al., 2016).

Perceived Benefit refers to the degree to which consumers expect they will gain when purchasing online content. Additional features can increase the benefit perceived by consumers, such as the privilege to read a variety of trial chapters on a platform without having to purchase the whole book, and privilege to access the latest chapter directly after being released (Zeithaml, 1988; Chu \& Lu, 2007; Lin et al., 2013). 
Perceived Sacrifice refers to the degree which consumers believe that they must pay to obtain the online content. The perception of sacrifice is heavier than usual when readers pay for content using a hybrid revenue model, which enables consumers, after a fee is paid, to access content for no extra cost over a period of time. The related increase in cost leads consumers to become less willing to pay or decide to switch to alternative products, such as e-books and printed books. Sacrifices, such as time, risk and unsatisfactory spending to obtain a product, increase when readers are required to purchase chapters in order to continue reading an unfinished novel, and they are not sure about timeliness and reliability of the author (Zeithaml, 1988; Chu \& Lu, 2007; Kim et al., 2007; Lin et al., 2013; Li \& Cheng 2014).

Perceived Value refers to an assessment of the utility of a customer for a product in respect of the willingness to exchange what they need to pay and what they expect to receive. As consumers can easily access free content from other resources, the value of platforms should be sufficiently worthwhile to encourage consumers to spend their resources such as time and money (Zeithaml, 1988; Monroe, 1991; Chu \& Lu, 2007; Lin et al., 2013; Li \& Cheng, 2014).

Purchase Intention on Online Literature refers to the possibility of a consumer to purchase an online content due to the valuation process of obtaining the content. A higher purchase intention can drive the consumer to actually make the purchase (Zeithaml, 1988; Chu \& Lu, 2007; Kim et al., 2007; Chi et al., 2011; Lin et al., 2013).

\section{Research Model and Hypotheses}

The model of intention to purchase chapters of online literature in this study (Figure 1) was developed with reference to previous research. The model indicates that favorable attitude from social norms construct, functional dependence on platform construct, and emotional attachment to content creator construct directly impact perceived benefit construct. In addition, perceived value construct is a mediator among perceived benefit construct, perceived sacrifice construct and purchase intention of online literature construct.

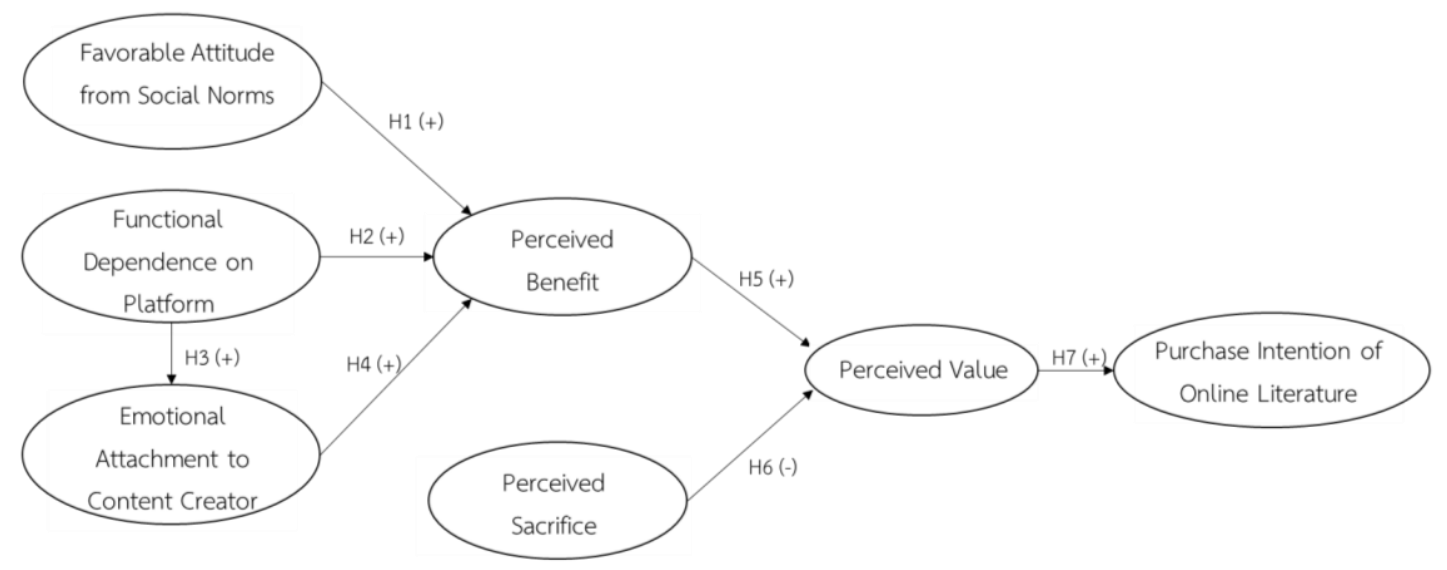

Figure 1. Model of Intention to Purchase Chapters of Online Literature

As individual choices are not always rational but may be affected by other people's opinions due to the need of social compliance (Kim \& Kankanhalli, 2009), favorable opinions toward a paid content could reduce uncertain feeling over the paid content as the value of a product has been highly appraised among other consumers ( $\mathrm{Li} \&$ Cheng, 2014). Thus, this research proposes a hypothesis that:

\section{H1: Favorable attitude from social norms has a positive relationship with perceived benefit}

In the process of valuation, satisfaction of consumers relies on the quality of products and features (Chu \& $\mathrm{Lu}$, 2007). Functional dependence could increase the perception of convenience, added value of the products, and eventually increase the contribution to the customers (Sohn \& Leckenby, 2007; Xu et al., 2012). Additionally, empirical evidence revealed that technical factors also have positive impact on perceived value (Wan et al., 2016). Thus, this research proposes a hypothesis that:

\section{H2: Functional dependence on platform has a positive relationship with perceived benefit}

Functional dependence on platforms was designed to support consumers in communication, consumption, discussion, and socialization (Wan et al., 2016). The better the features are, the more the users will engage on the 
platform (Sohn \& Leckenby, 2007; Xu et al., 2012). As a result, this functional dependence on the platform increases the degree of emotional attachment to the content creators, as supported by research in donation behavior (Wan et al., 2016). Thus, this research proposes a hypothesis that:

\section{creator}

H3: Functional dependence on platform has a positive relationship with emotional attachment to content

In the publishing field, readers tend to have greater emotional attachment to authors when they feel attached to books with the same genre. A perception of similarity between a user's personality and an author's personality can determine the degree of emotional attachment to the author (Saarinen \& Vakkari, 2013; Prasert, 2014). As has been shown by prior research, emotional attachment can also increase information value not only in the publishing field, but also in increased donations and increased purchasing intention in marketing contexts (Fedorikhin et al., 2008; Choi, 2013; Wan et al., 2016). Thus, this research proposes a hypothesis that:

\section{H4: Emotional attachment to content creator has a positive relationship with perceived benefit}

Rather than allowing consumers to experience free content on the internet, which can be of questionable quality, it is essential to let them perceive the worthiness of paying for the added value of the online content (Wang et al., 2005). A positive effect of perceived benefit with the willingness to pay for online content was also empirically confirmed (Chu \& Lu, 2007; Lin et al., 2013). Thus, this research proposes a hypothesis that:

\section{H5: Perceived benefit has a positive relationship with perceived value}

Unlike traditional content purchases, consumers making online purchases are unable to physically try and evaluate the real products before making a purchase decision (Li \& Cheng, 2014). In online literature platforms, the majority of content is written by amateurs where the quality is difficult to judge in advance (Ren \& Montgomery, 2012). The perception of sacrifice increases due to intangibility and insufficiency of trial periods and example contents (Li \& Cheng, 2014). In addition, Lin et al. (2013) supported that investing in unfamiliar technology, such as fee-based online services, entails risks during the consumption process. As confirmed by past studies, both monetary and non-monetary sacrifices have significant impact on perceived value which affects purchase behavior (Kim et al., 2007; Lin et al., 2013). Thus, this research proposes a hypothesis that:

\section{H6: Perceived sacrifice has a negative relationship with perceived value}

Consumers tend to purchase an online content if they perceive that the product has high value. On the other hand, the consumer feels unwilling to purchase an online content when the perceived sacrifice is higher than the benefit (Li \& Cheng, 2014). As consumers value reduction in sacrifice and increase in benefits differently (Monroe, 1991), empirical evidence supports that the greater the difference is between perceived benefit and sacrifice, the higher the consumers intention to purchase (Chu \& Lu, 2007; Lin et al., 2013). Thus, this research proposes a hypothesis that:

\section{H7: Perceived value has a positive relationship with purchase intention of online literature}

\section{Research Methodology}

This research collected data from participants who had experiences with free-based online literature platforms through websites and mobile applications in Thailand. The questionnaires were distributed via an online survey to participants of online literature communities. A total of 154 persons participated in this survey. The questions in the questionnaire are based on previous studies i.e., Chu \& Lu (2007); Li \& Cheng (2014); Prasert (2014); Wan et al. (2016), and is divided into three parts. The first part contains questions regarding usage behaviors on online literature platforms. The second part contains questions about factors influencing the intention in purchasing chapters of online literature. The final part contains questions about individual characteristics.

\section{Research Results}

One hundred and fifty-four respondents participated in this study. Responses from seven of the 154 participants $(4.6 \%)$ were not included in the analysis because they included outliers that anomalously misled the statistical analysis. Deletion of this unusable data reduced the sample size to 147 participants. The descriptive statistics of the usable data show normality of all constructs in the conceptual model. Therefore, the statistical assumptions are satisfied.

Principal factors extraction with varimax rotation was performed on items in the questionnaire. Seven factors were extracted. These factors are (1) Favorable attitude from social norms, (2) Functional dependence on platform, (3) Emotional attachment to content creator, (4) Perceived benefit, (5) Perceived sacrifice, (6) Perceived value and (7) Purchase intention of online literature. Table 1 contains descriptions of the factor analysis results. The factors attained Cronbach alpha reliabilities of $0.816,0.758,0.789,0.731,0.784,0.734$, and 0.893 respectively. 
Table 1. Mean, Standard Deviation, Factor Score, and Cronbach's Alpha of the Factors

\begin{tabular}{|c|c|c|c|}
\hline Factors & Mean & $\begin{array}{l}\text { Standard } \\
\text { Deviation }\end{array}$ & Factor Score \\
\hline \multicolumn{4}{|l|}{$\begin{array}{l}\text { Factor 1: Favorable Attitude from Social Norms } \\
(\% \text { of Variance }=73.372, \text { Cronbach's Alpha }=\mathbf{0 . 8 1 6})\end{array}$} \\
\hline $\begin{array}{l}\text { I tend to believe the positive reviews on social media about the novels I } \\
\text { should read }\end{array}$ & 3.347 & 0.7994 & 0.749 \\
\hline $\begin{array}{l}\text { I tend to believe the positive opinions from my friends about the novels I } \\
\text { should read }\end{array}$ & 3.755 & 0.8727 & 0.906 \\
\hline $\begin{array}{l}\text { I tend to believe the positive opinions from my colleagues/schoolmates } \\
\text { about the novels I should read }\end{array}$ & 3.476 & 0.8052 & 0.906 \\
\hline \multicolumn{4}{|l|}{$\begin{array}{l}\text { Factor 2: Functional Dependence on Platform } \\
(\% \text { of Variance }=\mathbf{5 8 . 0 8 9}, \text { Cronbach's Alpha }=\mathbf{0 . 7 5 8})\end{array}$} \\
\hline $\begin{array}{l}\text { Online literature platforms enable me to customize features to be suitable } \\
\text { for my style of use }\end{array}$ & 3.762 & 0.8467 & 0.751 \\
\hline $\begin{array}{l}\text { Online literature platforms enable me to follow the latest updates and } \\
\text { notices from my favorite authors }\end{array}$ & 3.878 & 0.8674 & 0.830 \\
\hline $\begin{array}{l}\text { Online literature platforms enable me to share my favorite contents through } \\
\text { social media }\end{array}$ & 3.939 & 0.8672 & 0.754 \\
\hline $\begin{array}{l}\text { Online literature platforms can suggest new novels which are similar to my } \\
\text { preference }\end{array}$ & 3.980 & 0.8619 & 0.709 \\
\hline \multicolumn{4}{|l|}{$\begin{array}{l}\text { Factor 3: Emotional Attachment to Content Creator } \\
(\% \text { of Variance }=\mathbf{7 0 . 6 3 4}, \text { Cronbach's Alpha }=\mathbf{0 . 7 8 9})\end{array}$} \\
\hline I am happy to read the novels from my favorite authors & 3.789 & 0.7958 & 0.808 \\
\hline I feel attached to my favorite authors & 4.082 & 0.6876 & 0.835 \\
\hline $\begin{array}{l}\text { I often follow works from the authors who have the style of writing suiting } \\
\text { my preference }\end{array}$ & 4.054 & 0.7919 & 0.877 \\
\hline \multicolumn{4}{|l|}{$\begin{array}{l}\text { Factor 4: Perceived Benefit } \\
(\% \text { of Variance }=65.251, \text { Cronbach's Alpha }=\mathbf{0 . 7 3 1})\end{array}$} \\
\hline $\begin{array}{l}\text { Online novel chapters enable me to read the content as soon as a new } \\
\text { chapter is released }\end{array}$ & 3.830 & 0.9678 & 0.834 \\
\hline Online novel chapters provide me a variety of genre & 3.810 & 0.9816 & 0.827 \\
\hline $\begin{array}{l}\text { Online novel chapters enable me to try a few chapters without purchasing } \\
\text { the whole book }\end{array}$ & 4.401 & 0.7644 & 0.760 \\
\hline \multicolumn{4}{|l|}{$\begin{array}{l}\text { Factor 5: Perceived Sacrifice } \\
(\% \text { of Variance }=\mathbf{7 0 . 0 8 4}, \text { Cronbach's Alpha }=\mathbf{0 . 7 8 4})\end{array}$} \\
\hline $\begin{array}{l}\text { The price charged per chapter is expensive when it is compared with the } \\
\text { entire book purchase (E-Book and printed book) }\end{array}$ & 4.129 & 0.9600 & 0.789 \\
\hline $\begin{array}{l}\text { Purchasing online literature incurs the risk that the author may not finish } \\
\text { the whole story that I'm reading }\end{array}$ & 4.347 & 0.9040 & 0.883 \\
\hline
\end{tabular}




\begin{tabular}{|c|c|c|c|}
\hline $\begin{array}{l}\text { I feel that the quality of online novel chapters are uncertain due to poor } \\
\text { literary style and misspelling }\end{array}$ & 4.272 & 0.9257 & 0.837 \\
\hline \multicolumn{4}{|l|}{$\begin{array}{l}\text { Factor 6: Perceived Value } \\
(\% \text { of Variance }=65.535, \text { Cronbach's Alpha }=\mathbf{0 . 7 3 4})\end{array}$} \\
\hline $\begin{array}{l}\text { Compared to the usage fee I need to pay, purchasing chapters of online } \\
\text { content themselves is worthy }\end{array}$ & 2.816 & 0.8915 & 0.713 \\
\hline $\begin{array}{l}\text { Compared to the time I need to put in, purchasing chapters of online } \\
\text { content is worthy }\end{array}$ & 3.497 & 0.9094 & 0.872 \\
\hline Overall, the use of a chapter purchase platform is worthy & 3.769 & 0.9071 & 0.836 \\
\hline \multicolumn{4}{|l|}{$\begin{array}{l}\text { Factor 7: Purchase Intention of Online Literature } \\
(\% \text { of Variance }=\mathbf{8 2 . 5 5 0 ,} \text { Cronbach's Alpha }=\mathbf{0 . 8 9 3})\end{array}$} \\
\hline I intend to purchase online chapters in the near future & 2.728 & 1.1004 & 0.922 \\
\hline I intend to purchase online chapters & 2.714 & 1.1170 & 0.934 \\
\hline $\begin{array}{l}\text { I intend to purchase online chapters more than entire book purchases } \\
\text { (E-Book and printed book) }\end{array}$ & 2.122 & 1.0590 & 0.869 \\
\hline
\end{tabular}

In this study, the participants are predominantly female (86.\%) and older than 30 years of age (31.3\%). Only $2 \%$ of participants are 15 years of age or lower. Nearly all participants either have already received bachelor degrees $(64 \%)$ or currently are undergraduate students $(35 \%)$. In addition, $29 \%$ of the participants are corporate employees. Over $60 \%$ of them earn less than US $\$ 670$ per month. Regarding which device is used, $46.3 \%$ and $34.4 \%$ of participants access online literature platforms via mobile phone and computers respectively. Ancient Chinese $(13.1 \%)$, fantasy $(12.9 \%)$, and romance $(11.9 \%)$ are the most favorite genres. Interestingly, over $50 \%$ of the participants access Dek-D.com and Tunwalai.com as their primary platforms.

The data was analyzed using a software package based on hierarchical regression analysis. To investigate direct and indirect effects of the examined factors, the mean scores of each factor in Table 1 were calculated. These mean scores were analyzed using hierarchical regression analysis. This research defines a statistical significant level at 0.05 or below. The standardized score and the highlights of statistical results are shown in Figure 2 and Table 2 respectively.

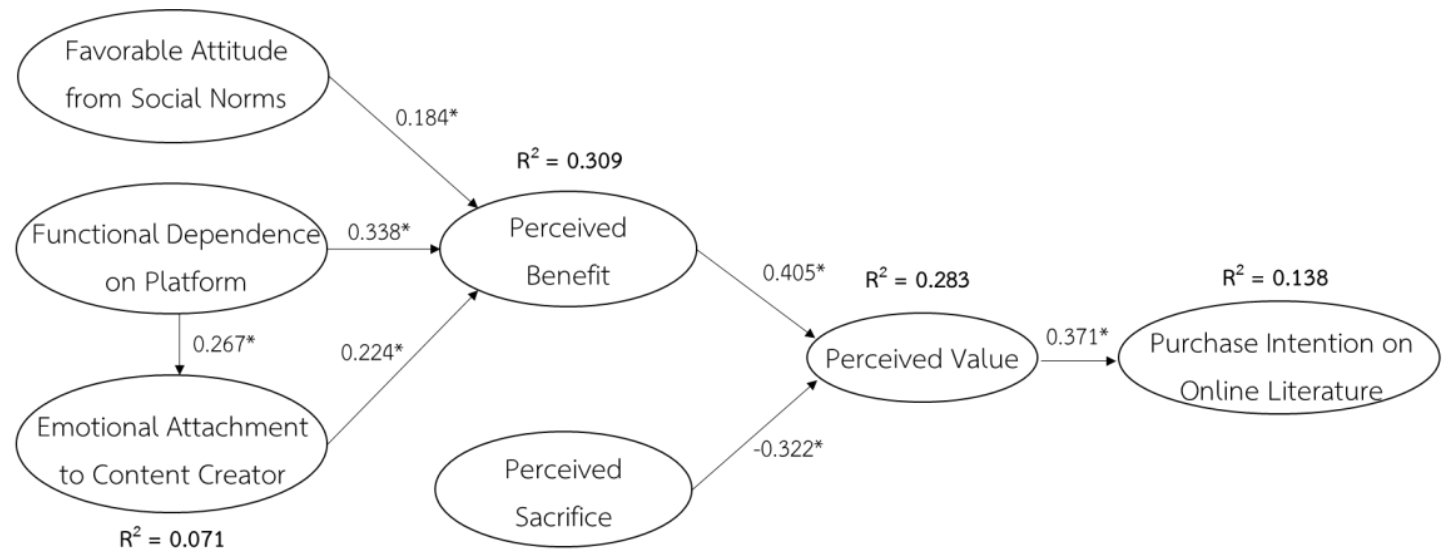

Figure 2. Structural Model Results 
Table 2. Direct, Indirect, and Total Effects of Variables in the Standardized Score

\begin{tabular}{|c|c|c|c|c|c|c|c|c|}
\hline \multirow[b]{2}{*}{ Dependent Variables } & \multirow[b]{2}{*}{$\mathbf{R}^{2}$} & \multirow[b]{2}{*}{ Effect } & \multicolumn{6}{|c|}{ Independent Variables } \\
\hline & & & 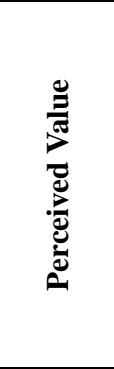 & 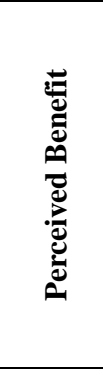 & 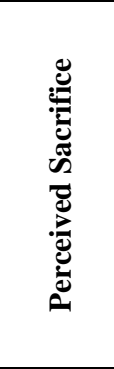 & 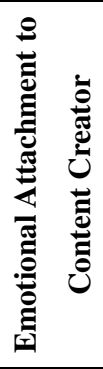 & 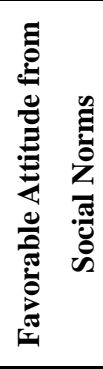 & 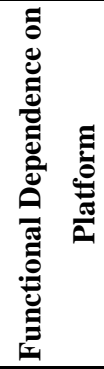 \\
\hline \multirow{3}{*}{$\begin{array}{l}\text { Purchase Intention of } \\
\text { Online Literature }\end{array}$} & \multirow{3}{*}{0.138} & Direct & $0.378 *$ & - & - & - & - & - \\
\hline & & Indirect & - & $0.150^{*}$ & $-0.119 *$ & - & - & - \\
\hline & & Total & $0.378 *$ & $0.150^{*}$ & $-0.119 *$ & - & - & - \\
\hline \multirow{3}{*}{ Perceived Value } & \multirow{3}{*}{0.283} & Direct & - & $0.405^{*}$ & $-0.322 *$ & - & - & - \\
\hline & & Indirect & - & - & - & $0.091 *$ & $0.075^{*}$ & $0.137 *$ \\
\hline & & Total & - & $0.405^{*}$ & $-0.322 *$ & $0.091 *$ & $0.075^{*}$ & $0.137 *$ \\
\hline \multirow{3}{*}{ Perceived Benefit } & \multirow{3}{*}{0.309} & Direct & - & - & - & $0.224 *$ & $0.184 *$ & $0.338 *$ \\
\hline & & Indirect & - & - & - & - & - & $0.060 *$ \\
\hline & & Total & - & - & - & $0.224 *$ & $0.184^{*}$ & $0.398 *$ \\
\hline \multirow{3}{*}{$\begin{array}{l}\text { Emotional Attachment to } \\
\text { Content Creator }\end{array}$} & \multirow{3}{*}{0.071} & Direct & - & - & - & - & - & $0.267^{*}$ \\
\hline & & Indirect & - & - & - & - & - & - \\
\hline & & Total & - & - & - & - & - & $0.267 *$ \\
\hline
\end{tabular}

The statistical results indicate that favorable attitude from social norms, functional dependence on platform, and emotional attachment to content creator have a significant influence on perceived benefit at an R-Square of $30.9 \%$. A discussion of the results of each factor follows.

- Favorable attitude from social norms has a significant direct effect at 95\% confidence level on perceived benefit with a coefficient of 0.184 . This supports Hypothesis 1 which states that favorable attitude from social norms has a positive relationship with perceived benefit. This result is consistent with Li \& Cheng (2014) who stated that favorable opinions of paid content could reduce uncertain feelings on the paid content, as the value of the product has been highly appraised by other consumers.

- Functional dependence on platform has significant direct and indirect effects, through emotional attachment to content creator on perceived benefit, at coefficients of 0.338 and 0.060 respectively. This supports Hypothesis 2 which states that functional dependence on platform has a positive relationship with perceived benefit. This result is consistent with Sohn \& Leckenby (2007) and Xu et al. (2012) who stated that functional dependence could increase the perception of convenience, add value to the products, and eventually increase contribution to the consumers.

- Emotional attachment to content creator has a significant direct effect at $95 \%$ confidence level on perceived benefit with a coefficient of 0.224 . This supports Hypothesis 4 which states that emotional attachment to content creator has a positive relationship with perceived benefit. This result is consistent with Wan et al. (2016), who stated that a strong attachment leads users to maintain a relationship with content creators. This enhances users' experiences, and encourages them to obtain related knowledge, innovative information, and interesting news, all of which can increase users' skill levels. Additionally, how much users engage in these activities is associated with the content creator's skill level. 
The statistical results indicate that functional dependence on platform has a significant direct influence at $95 \%$ confidence level on emotional attachment to content creator with a coefficient of 0.252 and R-Square of $7.1 \%$. This result supports Hypothesis 3 which states that functional dependence on platform has a positive relationship with emotional attachment to content creator. This result is consistent with Wan et al. (2016) who stated that the effectiveness of features provided on a platform allows users to spend more time on the topics they are interested in. While this is occurring, the users' intention to maintain long-term relationships with other users will strengthen.

The statistical results indicate that perceived benefit, perceived sacrifice, favorable attitude from social norms, functional dependence on platform, and emotional attachment to content creator have a significant influence at 95\% confidence level on the perceived benefit with an R-Square of $28.3 \%$. A discussion of the results of each factor follows.

- Perceived benefit has a significant direct effect at 95\% confidence level on perceived value with a coefficient of 0.405 . This supports Hypothesis 5 which states that perceived benefit has a positive relationship with perceived value. This is consistent with Wang et al. (2005), Chu \& Lu (2007), and Lin et al. (2013) who stated that perception of value increases with satisfaction of consumer's experiences related to the quality of products and features. Therefore, rather than letting consumers experience mediocre content among the free content on the internet, it is essential to get them to sense the worthiness in order to pay for the added value of online content.

- Perceived sacrifice has a significant direct effect at 95\% confidence level on perceived value with a coefficient of -0.322 . This supports Hypothesis 6 which states that perceived sacrifice has a negative relationship with perceived value. This is consistent with Ren \& Montgomery (2012), Li \& Cheng (2014), and Lin et al. (2013) who stated that the majority of content on online literature platforms is written by amateurs, and the quality is difficult to judge before reading or purchasing. The perception of value decreases due to intangibility and insufficiency of given trial periods and example content.

- Emotional attachment to content creator has a significant indirect effect through perceived benefit at $95 \%$ confidence level on perceived value with a coefficient of 0.091 .

- Favorable attitude from social norms has a significant indirect effect through perceived benefit at $95 \%$ confidence level on perceived value with a coefficient of 0.075 .

- Functional dependence on platform has a significant indirect effect through perceived benefit at $95 \%$ confidence level on perceived value with a coefficient of 0.137 .

The statistical results indicate that perceived value, perceived benefit, and perceived sacrifice have a significant influence at $95 \%$ confidence level on purchase intention of online literature with an R-Square of $13.8 \%$. A discussion of the results of each factor follows.

- Perceived value has a significant direct effect at $95 \%$ confidence level on the purchase intention of online literature with a coefficient of 0.378 . This supports Hypothesis 7 which states that perceived value has a positive relationship with purchase intention of online literature. This result is consistent with Zeithaml (1988), Chu \& Lu (2007), Kim et al. (2007), and Lin et al. (2013) who stated that purchase intention comes from the perception of a consumer on the benefit and sacrifice of obtaining a product through the evaluation of their experiences, preferences, and information from the external environment.

- Perceived benefit has a significant indirect effect through perceived value at $95 \%$ confidence level on perceived value with a coefficient of 0.150 .

- Perceived sacrifice has a significant indirect effect through perceived value at $95 \%$ confidence level on perceived value with a coefficient of -0.119 .

\section{Conclusion}

This research studies factors that influence the intention to purchase chapters of online literature. Quantitative approaches using online questionnaires were applied for gathering data. In addition, the value intention model, status quo bias theory, and integration of attachment theory and socio-technical systems were applied as guidelines in developing the conceptual model. The findings suggest that functional dependence on platform has a significant positive influence on emotional attachment to content creator, while perceived benefit is mostly affected by favorable attitude from social norms, functional dependence on platform, and emotional attachment to content creator. Perceived value is mostly influenced by perceived benefit with a positive relationship, and by perceived sacrifice with negative relationship. On the other hand, perceived value itself has a significant positive effect on the purchase intention of online literature. This research is one of the first to propose the combination of the value intention model, status quo bias theory, and integration of attachment theory and socio-technical 
systems in understanding the purchase intention of online literature. In addition, this study extended the combination model by adding perceived sacrifice variable from previous studies to fit this study.

\subsection{Practical Implications}

According to the significance of functional dependence on platform and emotional attachment to content creator, first, the platform should provide convenient channels for socialization among users and content creators to tighten their relationships. This feature assists practitioners to increase perceived benefits of the users on the platform. Second, apart from the first implication, communities - where groups of users share similar interests should be established to let users share their attitudes and discuss with each other about content. As a result, an increase in favorable attitudes from social norms should positively affect the perceived benefit of the users. Third, the practitioners should be more concerned about controlling and improving the quality of content as perceived sacrifice has a negative impact on perceived value and purchase intention. For example, the platform should provide a proofreading function for content creators. Last, the perceived benefit can be directly increased by publishing exclusive novels written by popular writers on a platform which cannot be found elsewhere.

\subsection{Limitation}

Practitioners should be aware of several limitations with this research. First, since most participants of the survey are female, the results may be different for male users. Second, since the survey was conducted in Thailand, this research may not be relevant to the behavior of foreign users because of cultural and social value differences. Third, this research cannot be applied to other fee-based platforms in Thailand - such as streaming movies and music - as consumers perceive value differently for each product or service. This is especially true for online literature platforms, which are perceived uniquely since they are filled with non-professional user-generated content, while most streaming products are well known nationwide.

\subsection{Future Research}

Even though chapter purchase platforms have been popular for years in many countries, it has only recently been adopted in Thailand. Most users haven't fully experienced fee-based online literature platforms and have never made an actual payment, as they often can access online literature free of charge, such as by using tokens from playing games and watching advertisements. As a result, present attitudes and behaviors of users might be unstable as the market is in an early stage. Thus, the users on these platforms should be resurveyed after the market becomes more stable.

Furthermore, from the results of this study, the effect from functional dependence on platform to emotional attachment to content creator was determined to have a low R-square of $7.1 \%$. This may be due to an insufficient number of relevant factors. Therefore, future research should study additional factors and bring them into the analysis in order to improve the R-square of the model. In addition, from the results of this study, it was found that functional dependence on platform plays a significant role in determining perceived benefit in online literature platform with a coefficient of 0.338 . Thus, future research should further study the factors influencing functional dependence on platform.

\section{References}

Aarseth, J. (1997). Cybertext: Perspectives on ergodic literature. Baltimore, Md: Johns Hopkins University Press.

Chi, H., Yeh, R., \& Tsai, C. (2011). The influences of perceived value on consumer purchase intention: the moderating effect of advertising endorser. Journal of International Management Studies, 6(1), 1-6.

Choi, N. (2013). Information systems attachment: An empirical exploration of its antecedents and its impact on community participation intention. Journal of the Association for Information Science and Technology, 64(11), 2354-2365. https://doi.org/10.1002/asi.22939

Chu, W., \& Lu, P. (2007). Factors influencing online music purchase intention in Taiwan: An empirical study based on the value-intention framework. Internet Research, 17(2), 139-155. https://doi.org/10.1108/10662240710737004

Dodds, B. \& Monroe, B. (1985). The effect of brand and price information on subjective product evaluations. Advances in Consumer Research, 12(1), 85-90.

Econ Chula \& SAB. (2015). The study of purchasing and reading behavioral of Thai people. Retrieved July 15, 2017, from http://www.pubat.or.th/document/20150224050823.pdf

Fedorikhin, A., Park, C. W., \& Thomson, M. (2008). Beyond fit and attitude: The effect of emotional attachment on consumer responses to brand extensions. Journal of Consumer Psychology, 18(4), 281-291. 
https://doi.org/10.1016/j.jcps.2008.09.006

Gallaugher, M., Auger, P. and BarNir A. (2001). Revenue Streams and Digital Content Providers: An Empirical Investigation. Information and Management, 38(7), 473-485. https://doi.org/10.1016/S0378-7206(00)00083-5

Holmes, J. G. (2000). Social relationships: The nature and function of relational schemas. European Journal of Social Psychology, 30(4), 447-495. https://doi.org/10.1002/1099-0992(200007/08)30:4<447::AID-EJSP10>3.0.CO;2-Q

Kim, W., \& Kankanhalli, A. (2009). Investigating User Resistance to Information Systems Implementation, A Status Quo Bias Perspective. MIS Quarterly, 33(3), 567-582. https://doi.org/10.2307/20650309

Kim, W., Chan, C., \& Gupta, S. (2007). Value-based adoption of Mobile Internet: An empirical investigation. Decision Support Systems, 43(1), 111-126. https://doi.org/10.1016/j.dss.2005.05.009

Kotilar, S. (2011). Freemium as a Business Model for Mobile Video. Master Thesis in Media Technology, KTH, Stockholm, Sweden.

Li, Z., \& Cheng, Y. (2014). From free to fee: exploring the antecedents of consumer intention to switch to paid online content. Journal of Electronic Commerce Research, 15(4), 281.

Lin, T. C., Hsu, J. S. C., \& Chen, H. C. (2013). Customer willingness to pay for online music: the role of free mentality. Journal of Electronic Commerce Research, 14(4), 315.

Liu, R. (2010). The business models of net literature in China. Master Thesis in Media Technology, KTH, Stockholm, Sweden.

Monroe, B. (1991). Pricing - Making Profitable Decisions. New York: McGraw-Hill.

National Statistical Office. (2016). The reading of population survey 2015. Retrieved July 15, 2017, from http://service.nso.go.th/nso/web/survey/surpop2-3-1.html

Ngamkaiwan, V. (2014). Factor affecting the acceptance to innovative electronic book of Thai consumers. Journal of the Association of Private Higher Education Institutions of Thailand, 2014, 3(2), 61-69.

Prasert, S. (2014). Factors influencing the purchase of novel digital book. Independent Study in Master of Science in Management Information Systems, Thammasat University.

Ren, X., \& Montgomery, L. (2012). Chinese online literature: creative consumers and evolving business models. Arts Marketing: an international journal, 2(2), 118-130. https://doi.org/10.1108/20442081211274002

Saarinen, K., \& Vakkari, P. (2013). A sign of a good book: readers' methods of accessing fiction in the public library. Journal of Documentation, 69(5), 736-754. https://doi.org/10.1108/JD-04-2012-0041

Samuelson, W., and Zeckhauser, R. (1988). Status Quo Bias in Decision Making. Journal of Risk and Uncertainty, 1(1), 7-59. https://doi.org/10.1007/BF00055564

Shirky, C. (2010). Cognitive Surplus: Creativity and Generosity in a Connected Age. Penguin Press, New York.

Sohn, D., \& Leckenby, D. (2007). A structural solution to communication dilemmas in a virtual community. Journal of Communication, 57(3), 435-449. https://doi.org/10.1111/j.1460-2466.2007.00351.x

Wan, J., Lu, Y., Wang, B., \& Zhao, L. (2016). How attachment influences users' willingness to donate to content creators in social media: A socio-technical systems perspective. Information \& Management, 54(7), 837-850. https://doi.org/10.1016/j.im.2016.12.007

Wang, C. L., Ye, L. R., Yue, Z., \& Nguyen, D. (2005). Subscription to fee-based online services: what makes consumer pay for online content?. Journal of Electronic Commerce Research, 6(4), 304-311.

Xu, C., Ryan, S., Prybutok, V., \& Wen, C. (2012). It is not for fun: An examination of social network site usage. Information \& Management, 49(5), 210-217. https://doi.org/10.1016/j.im.2012.05.001

Zeithaml, A. (1988). Consumer Perceptions of Price, Quality, and Value, A Means-end Model and Synthesis of Evidence. Journal of Marketing, 52(3), 2-22. https://doi.org/10.2307/1251446

\section{Copyrights}

Copyright for this article is retained by the author(s), with first publication rights granted to the journal.

This is an open-access article distributed under the terms and conditions of the Creative Commons Attribution license (http://creativecommons.org/licenses/by/4.0/). 